Jurnal Psikologi Teori \& Terapan

2013, Vol. 4, No. 1, 12 - 23

\title{
FENOMENA BODY DISSATISFACTION PADA PEREMPUAN ANGGOTA FITNESS CENTRE
}

\author{
Happy Yuanita dan Monique Elizabeth Sukamto \\ Fakultas Psikologi Universitas Surabaya
}

\begin{abstract}
Body dissatisfaction is a negative evaluation of the body that occurs due to the difference between the real body size and shape and the ideal one. Many women are dissatisfied with their body shape, which can be caused by the physical changes in each developmental stages and the prevailing beauty standard. One criteria of a beautiful woman is slim body. Body Mass Index (BMI) is the most common standard to evaluate one's body weight. One effort many women do to achieve the ideal body shape and weight is to exercise in fitness centre. This study was aimed to evaluate the differences in body dissatisfaction among women who were members offitness centre in terms of the developmental stages and level of obesity. Subjects were 150 women who became a member of fitness centre "X". Researchers used Body Shape Questionnaire (BSQ) to measure the level of body dissatisfaction. The results of this study showed that there was a difference of body dissatisfaction among women who were members of fitness centre " $X$ " in terms of developmental stages (chi square $=34.799$, sig. $=.000(<.05))$ and level of obesity $($ chi square $=32.134$, sig. $=.000(<.05)$ ). Highest level of body dissatisfaction was experienced by adolescent subjects, whereas the lowest one by middle adulthood subjects. Moreover, it was also found that subjects with obesity I and overweight experienced the highest level of body dissatisfaction.
\end{abstract}

Keywords: Body dissatisfaction, fitness centre, female, developmental stage, level of obesity.

\begin{abstract}
Abstrak: Body dissatisfaction adalah evaluasi negatif terhadap tubuh yang terjadi karena adanya perbedaan antara ukuran dan bentuk tubuh yang dimiliki saat ini dengan ukuran dan bentuk tubuh yang ideal. Banyak perempuan yang merasa tidak puas terhadap bentuk tubuh yang mereka miliki yang dapat disebabkan oleh perubahan fisik pada setiap tahap perkembangan dan standar kecantikan yang berlaku. Salah satu kriteria dari perempuan yang dianggap cantik adalah perempuan yang langsing. Indeks Massa Tubuh (IMT) merupakan standar yang paling umum untuk menilai berat badan seseorang. Salah satu usaha yang dilakukan banyak perempuan untuk mendapatkan bentuk tubuh dan berat badan yang ideal adalah berolahraga di fitness centre. Penelitian ini bertujuan untuk mengetahui perbedaan body dissatisfaction pada perempuan anggota fitness centre ditinjau dari tingkat kegemukan dan tahapan perkembangan. Subjek penelitian adalah 150 perempuan yang menjadi anggota di pusat kebugaran "X". Peneliti menggunakan Body Shape Questionnaire (BSQ) untuk mengukur tingkat body dissatisfaction. Hasil penelitian menunjukkan adanya perbedaan body dissatisfaction pada perempuan anggota fitness centre ditinjau dari tahapan perkembangan (chi square $=34.799$, sig. $=.000(<.05)$ ) dan tingkat kegemukan $($ chi square $=32.134$, sig. $=.000(<.05))$. Body dissatisfaction tertinggi dialami oleh subjek penelitian remaja dan terendah oleh dewasa madya. Selain itu, ditemukan juga bahwa body dissatisfaction tertinggi dialami oleh subjek dengan tingkat kegemukan obesitas I dan overweight.
\end{abstract}

Kata kunci: Body dissatisfaction, fitness centre, perempuan, tahapan perkembangan, tingkat kegemukan.

Olahraga fitness dikenal oleh masyarakat pada umumnya karena dilakukan di fitness centre atau yang lazim disebut pusat kebugaran. Fitness berhubungan dengan pergerakan tubuh 
dari fungsi internal serta kemampuan untuk memenuhi tantangan-tantangan fisik seharihari (Greenberg \& Pargman, dalam Sharkey, 2003). Pusat kebugaran saat ini selalu ramai dengan para anggota, baik laki-laki maupun perempuan yang ingin memiliki tubuh bugar dan sehat (Hutapea, 1996). Berbagai macam olahraga tersebut tentu dimanfaatkan oleh para anggota fitness centre dari berbagai usia untuk meningkatkan penampilannya agar menjadi lebih menarik (Carrol, 2003).

Standar kecantikan di masyarakat bahwa perempuan yang ideal adalah perempuan yang langsing menyebabkan banyak perempuan yang merasa tidak puas dengan berat badannya saat ini dan mendorong mereka untuk melakukan segala usaha untuk meraih standar ideal tersebut, salah satunya adalah melakukan olah raga (Mumford \& Choudry, 2000). Banyak perempuan melihat olahraga adalah sarana mempercepat proses menurunkan berat badan dan mereka mengadopsinya sebagai strategi utama untuk mengubah bentuk tubuh. Berolahraga untuk mengontrol berat badan sangat berkaitan dengan ketidakpuasan terhadap tubuh (body dissatisfaction) yang meningkat (Prichard \& Tiggemann, 2005).

Body dissatisfaction adalah komponen perseptif citra tubuh sebagai perbedaan antara ukuran tubuh ideal dan ukuran tubuh saat ini (Thompson, dalam Sivert \& Sinanovic, 2008). Senada dengan Thompson, Niide, Davis, Tse, Derauf, Harrigan, dan Yates (2011) mendefinisikan body dissatisfaction sebagai perbedaan antara tubuh yang dirasakan saat ini dengan ukuran dan bentuk seseorang yang ideal, sehingga semakin besar perbedaan tersebut akan semakin besar rasa tidak puas terhadap dirinya. Hall (2009) menyatakan body dissatisfaction sebagai evaluasi negatif yang subyektif dari seseorang terhadap bagian tubuhnya.

Faktor penyebab terjadinya body dissatisfaction pada perempuan adalah faktor sosial (tekanan sosial budaya) dan faktor biologis. Tekanan sosial budaya dari berbagai sumber, seperti keluarga dan lingkungan sebaya, memberikan tekanan-tekanan atau dorongan untuk menjadi langsing sesuai dengan standar ideal perempuan di masyarakat (Paxton, Eisenberg, \& Sztainer, 2006). Faktor biologis yang menyebabkan terjadinya body dissatisfaction pada perempuan salah satunya adalah perubahan fisik yang terjadi terkait pubertas, seperti timbulnya haid, dapat menumbuhkan perasaan malu karena budaya berasumsi bahwa perempuan haid lebih memancarkan pesan-pesan negatif, dan hal ini membuat perempuan merasa jauh dari standar ideal kecantikan (Giaber et al, dalam Stice \& Whitenton, 2002).

Hasil penelitian tentang Body Dissatisfaction and Eating Attitudes in Slimming and Fitness Gyms in London and Lahore yang dilakukan Mumford dan Choudry (2000) menyatakan bahwa kebanyakan perempuan lajang di London ingin terlihat menarik secara fisik untuk mendapatkan pasangan. Selain itu, banyak pula perempuan lajang menikmati persahabatan yang didapat dari pusat kebugaran. Motif utama mereka datang ke pusat kebugaran adalah untuk memperbaiki bentuk tubuh agar terlihat menarik.

Berikut adalah beberapa kutipan hasil wawancara awal yang dilakukan oleh peneliti terhadap tiga orang perempuan, masingmasing dari tahapan perkembangan remaja akhir, dewasa awal, dan dewasa madya, mengenai alasan mereka mengikuti olahraga di pusat kebugaran "X" di Surabaya:

“Aku ikut fitness karena disuruh mama danjuga banyak teman yang fitness disini, jadi senang bisa olahraga bareng-bareng. Aku nggak puas sama bentuk tubuhku saat ini karena perutku buncit, paha juga lebar" (Oliv, 18 tahun, pelajar, $161 \mathrm{~cm} / 66 \mathrm{~kg}$, IMT: 25,4) 
"Aku ikut fitness ini untuk mengembalikan berat
badanku karena aku habis melahirkan, jadi aku rajï
berolahraga agar badanku kembali seperti semula.
Aku sangat tidak puas dengan bentuk lengan, dada,
paha, dan perut karena jauh dari sempurna." (Nasha,
29 tahun, ibu rumah tangga, $164 \mathrm{~cm} / 84 \mathrm{~kg}$, IMT: 31,3)

"Alasan saya ikut fitness ini selain untuk menjaga kesehatan juga untuk mengencangkan tubuh saya agar tidak terlihat tua. Saya belum puas dengan tubuh saya secara keseluruhan, terutama pada bagian perut, pantat, dan paha." (Marissa, 43 tahun, pegawai swasta, $158 \mathrm{~cm} / 67$ kg, IMT: 26,9)

Dari hasil wawancara tersebut, dapat dilihat bahwa sebagian perempuan yang melakukan olahraga di fitness centre mengalami body dissatisfaction. Setiap perempuan memiliki alasan mengikuti fitness yang berbeda, yang kemungkinan berkaitan dengan tahap perkembangannya.

Pada masa remaja, perempuan sangat memperhatikan tubuhnya serta menghabiskan waktu yang lama dan usaha yang sungguhsungguh untuk mempercantik dirinya (Ibrahim, 2002). Hurlock (2002) membedakan masa remaja menjadi dua periode, yaitu masa remaja awal dengan rentang usia 13-16 tahun dan masa remaja akhir dengan rentang usia 1618 tahun. Pada masa remaja terjadi perubahanperubahan biologis, seperti pertambahan tinggi tubuh yang cepat, perubahan hormonal, dan kematangan seksual yang muncul ketika seseorang memasuki masa pubertas (Santrock, 2007). Pada masa pubertas, terjadi perubahan fisik seperti payudara membesar, tumbuhnya rambut di ketiak dan kemaluan, dan pinggul menjadi lebih lebar. Pada masa ini remaja disibukkan dengan perubahan tubuh dan mengembangkan citra individual mengenai gambaran tubuh mereka. Citra tubuh, minat berkencan, dan perilaku seksual dipengaruhi oleh perubahan pada masa pubertas (Santrock, 2002).

Kondisi fisik perempuan mencapai puncaknya pada masa dewasa awal. Batasan usia dewasa awal menurut Hurlock (2002) yaitu usia 18-40 tahun. Pada usia dewasa awal, perhatian pada kesehatan akan mulai meningkat dan perhatian pada pola makan, berat badan, dan olahraga juga mulai meningkat (Santrock, 2002). Namun, kondisi fisik perempuan juga mengalami penurunan selama masa ini. Grogan (2007) mengatakan bahwa perempuan di usia 20-30-an yang baru saja melahirkan merasa bahwa perubahan pasca melahirkan telah membuat tubuh mereka jauh dari standar ideal, seperti memiliki "perut lembek" dan "payudara turun". Banyak perempuan mengalami ketidaknyamanan fisik, merasa gemuk dan jelek pada saat hamil dan setelah melahirkan (Lips, 2006). Menurut Hurlock (2002), kesadaran akan kekurangan diri tersebut menimbulkan minat perempuan akan hal-hal yang menyangkut kecantikan, diet, dan olahraga karena perempuan menyadari bahwa penampilan fisik yang menarik sangat membantu statusnya dalam pekerjaan maupun perkawinan.

Perhatian terhadap penampilan fisik juga terjadi pada perempuan dewasa madya karena pada masa ini mulai terjadi proses menua secara gradual, seperti badan yang mulai mengendur, lemak mengumpul terutama sekitar perut dan paha, serta masalah penyakit (Santrock, 2002). Menurut Hurlock (2002), usia dewasa madya atau usia setengah baya berada pada rentang usia 40-60 tahun. Masa tersebut ditandai oleh adanya perubahan-perubahan jasmani dan mental. Olahraga merupakan alternatif yang lebih baik untuk mengurangi berat badan daripada menggunakan obat karena tidak hanya membakar kalori tetapi juga meningkatkan metabolisme (Santrock, 2002).

Berat badan atau tingkat kegemukan merupakan hal yang sangat penting bagi perempuan, baik secara fisik maupun psikologis. Hal ini terkait dengan status kesehatan, aktifitas fisik, citra tubuh, dan evaluasi diri. Definisi gemuk atau kegemukan sangat bervariasi, namun secara umum 
kegemukan adalah kelebihan berat badan yang melampaui berat badan normal. Secara klinis, seseorang dinyatakan mengalami kegemukan bila terdapat kelebihan berat badan sebesar $15 \%$ atau lebih dari berat badan idealnya. Idealnya, tubuh seorang perempuan terdiri dari $25-30 \%$ lemak. Bila lemak tubuh melebihi $30 \%$, maka orang tersebut sudah bisa dikategorikan gemuk atau obese (Misnadiarly, 2007). Indeks Massa Tubuh (IMT) adalah metode yang paling umum untuk menggambarkan standar berat badan (Olmsted \& McFarlane, 2004). Untuk mengetahui berat badan seseorang dinyatakan kurus, normal, atau gemuk dapat dilakukan dengan cara menghitung IMT, yaitu dengan membandingkan antara tinggi badan (m) dengan berat badan $(\mathrm{kg})$. Rumus untuk menghitung nilai IMT seseorang:

$\begin{gathered}\text { Indeks Massa Tubuh } \\ \text { (IMT) }\end{gathered}=\frac{\text { Berat Badan }(\mathrm{kg})}{\text { Tinggi Badan }{ }^{2}\left(\mathrm{~m}^{2}\right)}$

lebih tidak puas terhadap tubuhnya.

Selain fitness, para perempuan dapat melakukan usaha-usaha yang lain untuk mengatasi body dissatisfaction. Berikut adalah beberapa kutipan hasil wawancara peneliti kepada tiga perempuan anggota fitness centre terkait dengan usaha lain yang dilakukan:
"Usaha lain yang aku lakukan selain mengikuti olahraga di sini ya mengatur pola makan kayak semacam diet gitu dan juga bersepeda sama temen-temen tiap minggu pagi" (Oliv, 18 tahun, pelajar, $161 \mathrm{~cm} / 66 \mathrm{~kg}$ )
"Usaha lain yang aku lakukan yaitu mengonsumsi obat tradisional penurun badan (jamu) dan mengatur pola makan. Selain itu, saat ini aku mencoba untuk suntik vitamin $C$, yang khasiatnya bisa memutihkan badan secara menyeluruh, tapi hasilnya belum keliatan karena aku suntiknya seminggu yang lalu" (Nasha, 29 tahun, ibu rumah tangga, $164 \mathrm{~cm} / 84$ $\mathrm{kg})$

Tabel 1. Kategori Berat Badan

\begin{tabular}{cll}
\hline IMT $\left(\mathrm{kg} / \mathrm{m}^{2}\right)$ & \multicolumn{1}{c}{ Kategori Berat Badan } & \multicolumn{1}{c}{ Resiko Penyakit Penyerta } \\
\hline$<18.5$ & Kurang (underweight) & $\begin{array}{l}\text { Rendah (tetapi risiko terhadap } \\
\text { masalah klinis lain meningkat) }\end{array}$ \\
& & Rata-rata \\
$18.5-22.9$ & Normal / Ideal & Risiko meningkat \\
$23-24.9$ & Lebih (overweight) & Risiko sedang \\
$25-29.9$ & Kegemukan I (Obese I) & Risiko berbahaya \\
$=30$ & Kegemukan II (Obese II) & Sangat berbahaya \\
$=40$ & Kegemukan III (Obese III) &
\end{tabular}

IMT normal orang Asia adalah 18.5 22.9. Berat badan dengan IMT di bawah 18.5 dikategorikan sebagai berat badan kurang (underweight), sedangkan berat badan dengan IMT di atas 22.9 dikategorikan sebagai berat badan lebih (overweight) hingga kegemukan (obesitas).

Hasil penelitian dari Olmsted dan McFarlane (2004) menunjukkan bahwa perempuan yang memiliki kelebihan berat badan dan berat badan di bawah ideal (underweight) merasa sangat tidak puas dengan tubuhnya. Perempuan lajang yang memiliki IMT yang tinggi memiliki tingkat

\begin{abstract}
"Usaha yang saya lakukan untuk mengencangkan tubuh selain mengikuti fitness yaitu saya sering juga ke salon, melakukan treatment masker tubuh dan totok aura agar badan menjadi fresh dan tidak terlihat tua" (Marissa, 43 tahun, pegawai swasta, $158 \mathrm{~cm} / 67$ $\mathrm{kg})$
\end{abstract}

Dari hasil wawancara yang diperoleh, diketahui bahwa sebagian perempuan dari berbagai usia yang menjadi anggota di fitness centre juga melakukan usaha lain terkait dengan body dissatisfaction yang mereka alami, seperti mengatur pola makan atau diet, mengonsumsi ramuan tradisional (jamu), 
melakukan olah raga yang lain, bahkan ada pula yang melakukan suntik vitamin $\mathrm{C}$ dan perawatan kecantikan yang lain demi mendapatkan hasil yang mereka harapkan.

Berdasarkan beberapa uraian yang telah disebutkan di atas, maka peneliti ingin mengetahui apakah ada perbedaan body dissatisfaction pada perempuan yang menjadi anggota fitness centre ditinjau dari tahapan perkembangan dan tingkat kegemukan serta melihat usaha-usaha lain apa yang mereka lakukan terkait dengan body dissatisfaction yang dialami.

\section{METODE}

\section{Sampel}

Subjek penelitian ini adalah perempuan yang menjadi anggota di fitness centre " $\mathrm{X}$ " di Surabaya sejumlah 150 orang yang memiliki ciri-ciri sebagai berikut:

1. Berusia antara 16-60 tahun

2. Memiliki IMT yang tergolong underweight, normal, overweight, obesitas I, obesitas II

Teknik sampling pada penelitian ini menggunakan quota sampling, yaitu metode penetapan sampel dengan cara menentukan quota terlebih dahulu pada masing-masing kelompok, sebelum quota masing-masing kelompok terpenuhi maka pengumpulan data belum dianggap selesai. Dalam penelitian ini, peneliti menetapkan quota untuk tahapan perkembangan remaja akhir, dewasa awal, dan dewasa madya masing-masing adalah 50 orang.

\section{Teknik Pengumpulan Data}

Metode yang digunakan untuk mengumpulkan data adalah metode angket, yang terdiri atas dua macam angket:

\section{Angket terbuka}

Angket terbuka digunakan untuk mengungkap identitas subyek dan variabelvariabel yang mungkin memengaruhi seperti: lama bergabung, status perkawinan, usia, berat badan dan tinggi badan, berat badan ideal dan tinggi badan ideal, alasan melakukan olahraga, serta usaha lain yang dilakukan terkait body dissatisfaction.

\section{Body Shape Questionnaire (BSQ)}

Skala ini digunakan untuk mengukur body dissatisfaction, khususnya mengenai pengalaman merasa gemuk. BSQ terdiri dari 34 butir yang semuanya favorable (Cooper, Taylor, Cooper, \& Fairburn, dalam Marchiella, 2009). BSQ yang digunakan oleh peneliti merupakan skala yang telah diterjemahkan dan digunakan dalam penelitian Marchiella (2009). Aspek-aspek body dissatisfaction yang akan diukur dalam BSQ adalah: (1) distress yang disebabkan preokupasi terhadap berat badan dan bentuk tubuh, (2) malu untuk tampil di depan umum dan menghindari aktivitas yang mengekspos penampilan tubuh, (3) perasaan kegemukan yang berlebihan setelah makan.

Jawaban yang dapat dipilih berkisar antara tidak pernah (1), jarang (2), kadangkadang (3), sering (4), sangat sering (5), dan selalu (6). Semakin tinggi skor yang diperoleh, maka semakin tinggi pula taraf body dissatisfaction yang dialami subyek.

\section{Teknik Analisis Data}

Uji validitas skala yang dilakukan dalam penelitian ini adalah validitas isi, yaitu peneliti mencermati apakah butir-butir dari masingmasing skala dapat benar-benar mengukur aspek-aspek dari variabel penelitian. Selain itu, peneliti juga melakukan uji analisis butir dengan mencermati koefisien corrected itemtotal correlation dari masing-masing butir menggunakan teknik Alpha Cronbach dari SPSS 9 for Windows. Melalui uji analisis butir pada 34 butir BSQ, terdapat sepuluh butir yang 
dinyatakan gugur karena koefisien corrected item-total correlation $<0.3$. Rentang koefisien corrected item-total correlation dari butirbutir yang digunakan adalah $0.3401-0.8193$.

Uji reliabilitas suatu alat ukur menguji keajegan (konsistensi) dari hasil yang diperoleh. Suatu alat ukur dikatakan reliabel apabila memberikan hasil yang relatif sama dalam beberapa kali pengukuran terhadap kelompok yang sama. Untuk uji reliabilitas, digunakan teknik Alpha Cronbach dari SPSS 9 for Windows. Skala BSQ yang digunakan dalam penelitian ini memiliki koefisien Alpha sebesar $0.9332(\alpha>0.7)$, hal ini menunjukkan bahwa skala untuk mengukur body dissatisfaction yang digunakan dalam penelitian ini reliabel.

Sebelum dilakukan uji hipotesis terlebih dahulu dilakukan uji normalitas untuk mengetahui apakah penyebaran data dari variabel body dissatisfaction telah mengikuti distribusi kurve normal atau tidak. Berdasarkan hasil pengujian menggunakan teknik Kolmogorov-Smirnov, diperoleh nilai sig.= 0.000 (sig. < 0.05) yang berarti sebaran data variabel body dissatisfaction tersebut tidak normal. Oleh karena uji normalitas tidak terpenuhi, maka uji homogenitas (sebagai syarat berikutnya untuk pengujian statistik parametrik) tidak lagi perlu dilakukan dan uji hipotesis menggunakan statistik non-parametrik melalui teknik analisis Kruskal-Wallis. Untuk mengetahui rentang perbedaan pada tiap-tiap kelompok tahapan perkembangan dan tingkat kegemukan, juga dilakukan uji Mann-Whitney.

\section{HASIL DAN PEMBAHASAN}

\section{Hasil}

Berdasarkan tabel 2 diketahui bahwa sebagian besar (74\%) subjek remaja mengalami body dissatisfaction pada kategori tinggi. Sebagian besar subjek dewasa awal

Tabel 2.

Tabulasi silang antara tahapan perkembangan dengan body dissatisfaction

\begin{tabular}{|c|c|c|c|c|c|c|c|c|c|c|c|c|}
\hline \multirow{3}{*}{$\begin{array}{c}\text { Tahapan } \\
\text { Perkembangan }\end{array}$} & \multicolumn{10}{|c|}{ Body Dissatisfaction } & & \\
\hline & \multicolumn{2}{|c|}{$\begin{array}{l}\text { Sangat } \\
\text { tinggi }\end{array}$} & \multicolumn{2}{|c|}{ Tinggi } & \multicolumn{2}{|c|}{ Sedang } & \multicolumn{2}{|c|}{ Rendah } & \multicolumn{2}{|c|}{$\begin{array}{l}\text { Sangat } \\
\text { rendah }\end{array}$} & \multicolumn{2}{|c|}{ Total } \\
\hline & $f$ & $\%$ & $f$ & $\%$ & $f$ & $\%$ & $f$ & $\%$ & $f$ & $\%$ & $\mathrm{~F}$ & $\%$ \\
\hline Remaja & 0 & 0 & 37 & 74 & 7 & 14 & 3 & 6 & 3 & 6 & 50 & 100 \\
\hline Dewasa awal & 1 & 2 & 26 & 52 & 17 & 34 & 5 & 10 & 1 & 2 & 50 & 100 \\
\hline Dewasa madya & 0 & 0 & 9 & 18 & 30 & 60 & 8 & 16 & 3 & 6 & 50 & 100 \\
\hline Total & 1 & 100 & 72 & 100 & 54 & 100 & 16 & 100 & 7 & 100 & 150 & 100 \\
\hline
\end{tabular}

Tabel 3. Tabulasi silang antara tingkat kegemukan (IMT) dengan body dissatisfaction subjek penelitian

\begin{tabular}{|c|c|c|c|c|c|c|c|c|c|c|c|c|}
\hline \multirow{3}{*}{$\begin{array}{c}\text { Tingkat } \\
\text { Kegemukan (IMT) }\end{array}$} & \multicolumn{10}{|c|}{ Body Dissatisfaction } & \multirow{2}{*}{\multicolumn{2}{|c|}{ Total }} \\
\hline & \multicolumn{2}{|c|}{$\begin{array}{c}\text { Sangat } \\
\text { tinggi }\end{array}$} & \multicolumn{2}{|c|}{ Tinggi } & \multicolumn{2}{|c|}{ Sedang } & \multicolumn{2}{|c|}{ Rendah } & \multicolumn{2}{|c|}{$\begin{array}{l}\text { Sangat } \\
\text { rendah }\end{array}$} & & \\
\hline & $f$ & $\%$ & $f$ & $\%$ & $f$ & $\%$ & $f$ & $\%$ & $f$ & $\%$ & $\mathrm{f}$ & $\%$ \\
\hline Kurang & 0 & 0 & 0 & 0 & 1 & 20 & 2 & 40 & 2 & 40 & 5 & 100 \\
\hline Normal & 0 & 0 & 8 & 24.2 & 13 & 39.4 & 7 & 21.2 & 5 & 15.2 & 33 & 100 \\
\hline Overweight & 1 & 2.8 & 19 & 52.8 & 15 & 41.7 & 1 & 2.8 & 0 & 0 & 36 & 100 \\
\hline Obesitas I & 0 & 0 & 42 & 64.6 & 18 & 27.7 & 5 & 7.7 & 0 & 0 & 65 & 100 \\
\hline Obesitas II & 0 & 0 & 3 & 27.3 & 7 & 63.6 & 1 & 9.1 & 0 & 0 & 11 & 100 \\
\hline Total & 1 & 100 & 72 & 100 & 54 & 100 & 16 & 100 & 7 & 100 & 150 & 100 \\
\hline
\end{tabular}


mengalami body dissatisfaction pada kategori tinggi (52\%) dan sedang (34\%), sedangkan sebagian besar subjek dewasa madya $(60 \%)$ mengalami body dissatisfaction pada kategori sedang.

Dari tabel 3 dapat diketahui bahwa sebagian besar (40\%) subjek yang memiliki berat badan pada kategori kurang mengalami body dissatisfaction pada kategori rendah dan sangat rendah; sebagian besar (39.4\%) subjek dengan berat badan normal mengalami body dissatisfaction pada kategori sedang; sebagian besar subjek yang memiliki berat badan overweight $(52.8 \%)$ dan obesitas I (64.6\%) mengalami body dissatisfaction pada kategori tinggi; sebagian besar (63.6\%) subjek yang memiliki berat badan pada kategori obesitas II mengalami body dissatisfaction pada kategori sedang.

Tabel 4 menggambarkan bahwa sebagian besar subjek yang mengharapkan memiliki berat badan pada kategori kurang mengalami body dissatisfaction pada kategori sedang (43.8\%) dan tinggi (40.6\%); sebagian besar (59.2\%) subjek yang mengharapkan memiliki berat badan normal mengalami body dissatisfaction pada kategori tinggi; sebagian besar subjek yang mengharapkan memiliki berat badan pada kategori overweight mengalami body dissatisfaction pada kategori sedang (46.2\%) dan rendah (38.5\%); sebagian besar subjek yang mengharapkan memiliki berat badan pada kategori obesitas I juga mengalami body dissatisfaction pada kategori sedang (42.9\%) dan rendah (42.9\%).

Tabel 5 menunjukkan bahwa pihak yang paling banyak memberi dorongan kepada subjek remaja (43\%), dewasa awal (56\%), dan dewasa madya (52\%) untuk mengikuti olahraga di fitness centre adalah diri mereka sendiri. Berikutnya, pihak lain yang juga banyak memberi dorongan untuk mengikuti olahraga di fitness centre pada subjek remaja (31\%) dan dewasa madya (32\%) adalah teman, sedangkan pada subjek dewasa awal $(25 \%)$ adalah keluarga.

Tabel 4. Tabulasi silang antara tingkat kegemukan (IMT) yang diharapkan dengan body dissatisfaction subjek penelitian

\begin{tabular}{|c|c|c|c|c|c|c|c|c|c|c|c|c|}
\hline \multirow{3}{*}{$\begin{array}{c}\text { Tingkat } \\
\text { Kegemukan (IMT) } \\
\text { yang Diharapkan }\end{array}$} & \multicolumn{10}{|c|}{ Body Dissatisfaction } & \multirow{2}{*}{\multicolumn{2}{|c|}{ Total }} \\
\hline & \multicolumn{2}{|c|}{$\begin{array}{c}\text { Sangat } \\
\text { tinggi }\end{array}$} & \multicolumn{2}{|c|}{ Tinggi } & \multicolumn{2}{|c|}{ Sedang } & \multicolumn{2}{|c|}{ Rendah } & \multicolumn{2}{|c|}{$\begin{array}{l}\text { Sangat } \\
\text { rendah }\end{array}$} & & \\
\hline & $f$ & $\%$ & $f$ & $\%$ & $f$ & $\%$ & $f$ & $\%$ & $f$ & $\%$ & $f$ & $\%$ \\
\hline Kurang & 1 & 3.1 & 13 & 40.6 & 14 & 43.8 & 2 & 6.3 & 2 & 6.3 & 32 & 100 \\
\hline Normal & 0 & 0 & 58 & 59.2 & 31 & 31.6 & 6 & 6.1 & 3 & 3.1 & 98 & 100 \\
\hline Overweight & 0 & 0 & 1 & 7.7 & 6 & 46.2 & 5 & 38.5 & 1 & 7.7 & 13 & 100 \\
\hline Obesitas I & 0 & 0 & 0 & 0 & 3 & 42.9 & 3 & 42.9 & 1 & 14.3 & 7 & 100 \\
\hline Total & 1 & 100 & 72 & 100 & 54 & 100 & 16 & 100 & 7 & 100 & 150 & 100 \\
\hline
\end{tabular}

Tabel 5. Pihak yang memberi dorongan kepada subjek penelitian untuk mengikuti olahraga di fitness centre

\begin{tabular}{lllllll}
\hline Pihak yang Mendorong & Remaja & $\%$ & D.Awal & $\%$ & D.Madya & $\%$ \\
\hline Keluarga & 18 & $25 \%$ & $\mathbf{2 0}$ & $\mathbf{2 5} \%$ & 11 & $16 \%$ \\
Teman & $\mathbf{2 2}$ & $\mathbf{3 1} \%$ & 14 & $17 \%$ & $\mathbf{2 2}$ & $\mathbf{3 2} \%$ \\
Diri sendiri & $\mathbf{3 1}$ & $\mathbf{4 3} \%$ & $\mathbf{4 5}$ & $\mathbf{5 6} \%$ & $\mathbf{3 6}$ & $\mathbf{5 2} \%$ \\
Lainnya: Pacar & 1 & $1 \%$ & 2 & $2 \%$ & & \\
\hline Total & 72 & $100 \%$ & 81 & $100 \%$ & 69 & $100 \%$ \\
\hline
\end{tabular}

*subjek boleh memilih jawaban lebih dari satu 
Tabel 6. Kepuasan subjek penelitian dalam mengikuti olahraga

\begin{tabular}{lll}
\hline Tingkat Kepuasan & $\mathrm{f}$ & Persentase \\
\hline Sangat puas & 26 & $17 \%$ \\
Puas & $\mathbf{9 8}$ & $\mathbf{6 5} \%$ \\
Biasa & 25 & $17 \%$ \\
Tidak puas & 1 & $1 \%$ \\
\hline Total & 150 & $100 \%$ \\
\hline
\end{tabular}

Tabel 6 menunjukkan bahwa sebagian besar $(65 \%)$ subjek penelitian merasa puas mengikuti olahraga difitness centre.
(41\%), dewasa awal (45\%), dan dewasa madya (28\%) setelah menjadi anggota fitness centre adalah berat badan menurun. Selain itu, manfaat terbanyak berikutnya yang dirasakan oleh subjek remaja adalah kepercayaan diri meningkat (19\%) dan menambah teman (18\%); manfaat terbanyak berikutnya yang dirasakan oleh subjek dewasa awal (18\%) adalah kepercayaan diri meningkat, sedangkan pada subjek dewasa madya (25\%) adalah ketegangan psikis berkurang.

Tabel 7. Aktifitas subjek penelitian saat berada di fitness centre

\begin{tabular}{lcrrrrr}
\hline \multicolumn{1}{c}{ Aktivitas } & Remaja & \multicolumn{1}{c}{$\%$} & D.Awal & \multicolumn{1}{c}{ \% } & D.Madya & $\%$ \\
\hline Olahraga & $\mathbf{5 0}$ & $\mathbf{5 2} \%$ & $\mathbf{4 7}$ & $\mathbf{5 4} \%$ & $\mathbf{5 0}$ & $\mathbf{6 2} \%$ \\
Bertemu teman \& ngobrol & 18 & $19 \%$ & 12 & $14 \%$ & $\mathbf{1 9}$ & $\mathbf{2 4} \%$ \\
Menikmati fasilitas & $\mathbf{2 8}$ & $\mathbf{2 9} \%$ & $\mathbf{2 6}$ & $\mathbf{3 0} \%$ & 11 & $14 \%$ \\
Lainnya: menawarkan & & & 2 & $2 \%$ & & \\
barang & & & & & & \\
\hline Total & 96 & $100 \%$ & 87 & $100 \%$ & 80 & $100 \%$ \\
\hline
\end{tabular}

*subjek boleh memilih jawaban lebih dari satu

Tabel 7 menunjukkan bahwa aktivitas yang paling banyak dilakukan oleh subjek remaja (52\%), dewasa awal (54\%), dan dewasa madya (62\%) saat berada di fitness centre adalah olahraga. Selain itu, aktivitas berikutnya yang paling banyak dilakukan oleh subjek remaja (29\%) dan dewasa awal (30\%) adalah menikmati fasilitas di fitness centre, sedangkan subjek dewasa madya (24\%) lebih memilih bertemu teman dan mengobrol.
Tabel 9 menunjukkan usaha lain yang paling banyak dilakukan oleh subjek remaja (40\%), dewasa awal (32\%), dan dewasa madya (29\%) selain mengikuti olahraga di fitness centre yaitu diet (mengatur pola makan). Selain itu, usaha terbanyak berikutnya pada subjek remaja $(37.5 \%)$ dan dewasa awal (21\%) adalah melakukan olahraga lain, seperti: bersepeda, berenang, basket, bulu tangkis, sedangkan pada subjek

Tabel 8. Manfaat yang dirasakan setelah menjadi anggota fitness centre

\begin{tabular}{lllllll}
\hline \multicolumn{1}{c}{ Manfaat } & Remaja & $\%$ & D.Awal & $\%$ & D.Madya & $\%$ \\
\hline Berat badan menurun & $\mathbf{4 6}$ & $\mathbf{4 1} \%$ & $\mathbf{4 9}$ & $\mathbf{4 5} \%$ & $\mathbf{3 6}$ & $\mathbf{2 8} \mathbf{\%}$ \\
Berat badan meningkat & 4 & $3 \%$ & 3 & $3 \%$ & 6 & $5 \%$ \\
Terbentuknya otot tubuh & 11 & $10 \%$ & 8 & $7 \%$ & 11 & $9 \%$ \\
Daya tahan tubuh meningkat & 8 & $7 \%$ & 10 & $9 \%$ & 16 & $12 \%$ \\
Ketegangan psikis berkurang & 2 & $2 \%$ & 9 & $8 \%$ & $\mathbf{3 2}$ & $\mathbf{2 5} \%$ \\
Kepercayaan diri meningkat & $\mathbf{2 1}$ & $\mathbf{1 9} \%$ & $\mathbf{2 0}$ & $\mathbf{1 8} \%$ & 22 & $17 \%$ \\
Teman dan kenalan & $\mathbf{2 0}$ & $\mathbf{1 8} \%$ & 11 & $10 \%$ & 5 & $4 \%$ \\
bertambah & & & & & & \\
\hline Total & 112 & $100 \%$ & 110 & $100 \%$ & 128 & $100 \%$ \\
\hline
\end{tabular}

*subjek boleh memilih jawaban lebih dari satu

Tabel 8 menunjukkan manfaat yang paling banyak dirasakan oleh subjek remaja dewasa madya (19\%) adalah mengonsumsi obat pelangsing. 
Tabel 9. Usaha lain yang dilakukan selain mengikuti olahraga di fitness centre

\begin{tabular}{lcccccc}
\hline \multicolumn{1}{c}{ Usaha Lain } & Remaja & $\%$ & D.Awal & $\%$ & D.Madya & $\%$ \\
\hline \multicolumn{1}{c}{ Diet } & $\mathbf{4 5}$ & $\mathbf{4 0 \%}$ & $\mathbf{4 0}$ & $\mathbf{3 2} \%$ & $\mathbf{3 9}$ & $\mathbf{2 9} \%$ \\
$\begin{array}{l}\text { Mengonsumsi obat } \\
\text { pelangsing }\end{array}$ & 11 & $10 \%$ & 17 & $14 \%$ & $\mathbf{2 5}$ & $\mathbf{1 9 \%}$ \\
$\begin{array}{l}\text { Mengonsumsi jamu } \\
\text { Kegiatan medis }\end{array}$ & 4 & $3.5 \%$ & 8 & $6 \%$ & 23 & $17 \%$ \\
$\begin{array}{l}\text { Melakukan olahraga lain } \\
\text { Melakukan akupuntur }\end{array}$ & $\mathbf{4 2}$ & $\mathbf{3 7 . 5} \%$ & $\mathbf{2 6}$ & $\mathbf{2 1} \%$ & 22 & $16 \%$ \\
$\begin{array}{l}\text { Melakukan perawatan di } \\
\text { klinik kecantikan }\end{array}$ & 8 & $\mathbf{1} \%$ & 4 & $3 \%$ & 2 & $2 \%$ \\
$\begin{array}{l}\text { Melakukan perawatan di } \\
\text { klinik pelangsingan }\end{array}$ & & 18 & $15 \%$ & 11 & $8 \%$ \\
$\begin{array}{l}\text { Lainnya: Minum susu } \\
\text { Menambah nafsu } \\
\text { makan }\end{array}$ & 1 & $1 \%$ & 2 & $2 \%$ & 2 & $2 \%$ \\
\hline Total & 112 & $100 \%$ & 124 & $100 \%$ & 132 & $100 \%$ \\
\hline
\end{tabular}

*subjek boleh memilih jawaban lebih dari satu

\section{Pembahasan}

Hasil uji hipótesis menggunakan teknik Kruskall-Wallis menunjukkan bahwa ada perbedaan body dissatisfaction ditinjau dari tahapan perkembangan (chi square $=34.799$, $\mathrm{df}=2$, sig. $=0.000(<0.05))$. Selanjutnya, peneliti menggunakan uji Mann-Whitney untuk mengetahui signifikansi perbedaan body dissatisfaction dari masing-masing tahapan perkembangan. Berdasarkan uji Mann-Whitney, diketahui bahwa body dissatisfaction tertinggi dialami oleh remaja, diikuti oleh dewasa awal, dan yang terendah adalah dewasa madya. Melalui tabulasi silang antara tahapan perkembangan subjek penelitian dengan body dissatisfaction (tabel 2) dapat dilihat bahwa sebagian besar subjek remaja mengalami body dissatisfaction pada taraf yang lebih tinggi daripada sebagian besar subjek dewasa awal dan dewasa madya.

Menurut Santrock (2002), faktor yang menyebabkan perempuan remaja, dewasa awal, dan dewasa madya mengalami body dissatisfaction adalah perubahan fisik yang mereka alami dengan membandingkan tubuh mereka dengan stándar ideal di masyarakat. Pada masa remaja, perubahan-perubahan fisik yang terjadi pada masa pubertas, ditambah dengan meningkatnya kesadaran akan identitas diri dan munculnya ketertarikan dengan lawan jenis menyebabkan remaja perempuan semakin menyadari akan pentingnya daya tarik fisik dan melakukan usaha-usaha untuk memperbaiki penampilannya. Perempuan dewasa awal juga menyadari bahwa penampilan fisik yang menarik sangat membantu statusnya dalam bidang pekerjaan dan perkawinan. Pada masa ini penampilan fisik yang menarik sangat penting untuk mencapai status sosial yang lebih tinggi terkait tugas perkembangan dewasa awal yang mencakup mendapatkan pekerjaan, memilih pasangan hidup, dan membentuk suatu keluarga (Hurlock, 2002). Jadi, penampilan fisik pada perempuan remaja dan dewasa awal menjadi hal yang penting karena terkait dengan tugas perkembangan. Pada masa dewasa madya, perempuan tidak terlalu merisaukan penampilan dan kecantikan karena mereka sudah lebih menerima kondisi fisik apa adanya serta lebih memrioritaskan perannya dalam keluarga dan bangga akan utuhnya keluarga (Hurlock, 2002).

Perempuan yang merasa tidak puas dengan tubuhnya akan melakukan usahausaha untuk memperbaikinya, salah satunya 
adalah dengan mengikuti olahraga di fitness centre. Hasil penelitian (tabel 5) menunjukkan bahwa dorongan yang terbesar untuk mengikuti olahraga di fitness centre pada sebagian besar subjek remaja, dewasa awal, dan dewasa madya bersumber dari diri mereka sendiri. Selanjutnya, pihak lain yang juga banyak memberi dorongan untuk mengikuti olahraga di fitness centre pada subjek remaja dan dewasa madya adalah teman, sedangkan pada subjek dewasa awal adalah keluarga.

Fitness centre merupakan salah satu tempat untuk meningkatkan kebugaran jasmani, banyak program yang ditawarkan oleh pusat kebugaran baik alternatif tempat atau jenis latihan bagi perempuan untuk berolahraga (Giriwijoyo, dalam Handayani 2004). Fitness centre " $\mathrm{X}$ " menawarkan beberapa kegiatan diantaranya senam aerobic, aqua-robic, body language, step reebok, taebo, fun run, dan fitness. Selain itu, fitness centre ini juga menyediakan sarana olahraga yang lain, seperti: kolam renang, squash, tenis meja, bola basket, bulu tangkis, dan tenis lapangan. Fasilitas yang disediakan oleh Fitness Centre " $\mathrm{X}$ " ini antara lain fasilitas mandi air panas, sauna, ruang senam yang luas dan nyaman dengan full AC, computerized fitness machines, indoor jogging track dan swimming pool, whirlpool, dan konsultasi dokter.

Pada penelitian ini, sebagian besar subjek penelitian merasa puas mengikuti olahraga di fitness centre (tabel 6). Aktivitas yang paling banyak dilakukan oleh subjek remaja, dewasa awal, dan dewasa madya saat berada di fitness centre adalah berolahraga. Selain itu, aktivitas yang cukup banyak dilakukan oleh subjek remaja dan dewasa awal adalah menikmati fasilitas di fitness centre, sedangkan subjek dewasa madya lebih memilih untuk bertemu teman dan mengobrol (tabel 7).

Banyak manfaat yang diperoleh dengan melakukan olahraga rutin, yaitu membuat otot-otot menjadi kokoh dan lentur, kulit menjadi sehat dan elastis, pernafasan menjadi lebih baik, postur tubuh dapat diperbaiki, kegemukan dan kekurusan dapat diatasi (Retno, 1996). Hal ini sesuai dengan hasil penelitian (tabel 8) yang menunjukkan bahwa manfaat yang paling banyak dirasakan oleh subjek remaja, dewasa awal, dan dewasa madya setelah menjadi anggota fitness centre adalah berat badan menurun. Selain itu, manfaat terbanyak berikutnya yang dirasakan oleh subjek remaja adalah kepercayaan diri meningkat dan menambah teman, pada subjek dewasa awal adalah kepercayaan diri meningkat, sedangkan pada subjek dewasa madya adalah ketegangan psikis berkurang.

Perempuan yang memiliki bentuk tubuh yang tidak sesuai dengan yang diharapkan akan menyadari kekurangankekurangan dirinya dan menyadari bahwa mereka tidak dapat menghapus kekurangan dirinya tanpa melakukan usaha memperbaiki penampilannya. Usaha lain (tabel 9) yang paling banyak dilakukan oleh subjek remaja, dewasa awal, dan dewasa madya selain melakukan olah raga di fitness centre adalah diet (mengatur pola makan). Selain itu, usaha terbanyak berikutnya pada subjek remaja dan subjek dewasa awal adalah melakukan olahraga lain, seperti: bersepeda, berenang, basket, bulu tangkis, sedangkan subjek dewasa madya memilih mengonsumsi obat pelangsing.

Hasil uji hipótesis berikutnya menggunakan teknik Kruskall-Wallis menunjukkan bahwa ada perbedaan body dissatisfaction ditinjau dari tingkat kegemukan (chi square $=32.134, \mathrm{df}=4$, sig. $=$ $0.000(<.05))$. Selanjutnya, hasil uji MannWhitney menunjukkan bahwa ada perbedaan body dissatisfaction yang signifikan antara tingkat kegemukan underweight-overweight $($ sig. $=.003)$, underweight - obesitas I (sig.= $.001)$, underweight - obesitas II (sig.= .020), normal-overweight $($ sig. $=.000)$, dan normal 
- obesitas I (sig. $=.000)$. Namun, uji MannWhitney menunjukkan bahwa tidak ada perbedaan body dissatisfaction yang signifikan antara tingkat kegemukan underweight - normal (sig.= .073), normal obesitas II (sig.= .076), overweight - obesitas I (sig.= .485), overweight - obesitas II (sig.= .297), dan obesitas I - obesitas II (sig.= .128). Hasil tersebut diperjelas melalui tabulasi silang antara tingkat kegemukan (Indeks Massa Tubuh) dengan body dissatisfaction pada subjek penelitian (tabel 3). Data yang diperoleh menunjukkan bahwa sebagian besar subjek penelitian yang memiliki berat badan pada kategori kurang (underweight) dan normal mengalami body dissatisfaction pada taraf yang lebih rendah daripada sebagian besar subjek yang memiliki berat badan pada kategori overweight dan obesitas I.

Hasil ini sesuai dengan temuan Olmsted dan McFarlane (2004) bahwa perempuan yang mengalami kelebihan berat badan dan obesitas merasa sangat tidak puas dengan tubuhnya. Menurut Sarwer, Thompson, dan Cash (2005), perempuan yang mengalami kelebihan berat badan dan obesitas mengalami body dissatisfaction yang lebih besar dibandingkan dengan perempuan yang memiliki berat badan normal. Fenomena menarik yang dapat diamati pada penelitian ini adalah sebagian besar subjek dengan tingkat kegemukan obesitas II, ternyata mengalami body dissatisfaction pada kategori sedang. Tingkat kegemukan yang berbeda jauh dari kondisi normal kemungkinan menyebabkan sebagian besar perempuan dengan tingkat kegemukan obesitas II cenderung menerima kondisi tubuh mereka, walaupun mereka tetap melakukan usaha dengan berolahraga difitness centre.

Standar kecantikan yang berlaku di masyarakat memandang perempuan yang ideal adalah perempuan yang langsing. Hal ini membuat para perempuan merasa penting untuk mendapatkan penilaian dari orang lain, sehingga perempuan cenderung membandingkan penampilannya dengan orang lain (Suprapto \& Aditomo, 2007). Pada penelitian ini diperoleh hasil yang menunjukkan bahwa sebagian besar subjek penelitian mengharapkan memiliki berat badan pada kategori normal/ideal, bahkan cukup banyak subjek penelitian yang mengharapkan memiliki berat badan kurang (underweight). Pada tabulasi silang antara tingkat kegemukan (IMT) yang diharapkan dengan body dissatisfaction (tabel 4), dapat dilihat bahwa sebagian besar subjek yang mengharapkan memiliki berat badan pada kategori normal dan underweight mengalami body dissatisfaction pada taraf yang lebih tinggi daripada sebagian besar subjek yang mengharapkan memiliki berat badan pada kategori overweight dan obesitas I.

\section{SIMPULAN}

Hasil dari penelitian ini menunjukkan bahwa ada perbedaan body dissatisfaction pada perempuan anggota fitness centre ditinjau dari tahapan perkembangan dan tingkat kegemukan. Body dissatisfaction tertinggi dialami oleh subjek penelitian remaja dan subjek penelitian dengan tingkat kegemukan obesitas I dan overweight. Manfaat mengikuti olahraga di fitness centre yang paling dirasakan oleh subjek penelitian adalah berat badan menurun, selain itu manfaat lain, seperti kepercayaan diri bertambah, menambah teman, dan berkurangnya ketegangan psikis juga cukup banyak dirasakan oleh subjek penelitian. Selain mengikuti olahraga di fitness centre, usaha lain yang paling banyak dilakukan oleh sebagian besar subjek penelitian terkait body dissatisfaction yang mereka alami adalah berdiet (mengatur pola makan), melakukan olahraga lain, seperti bersepeda, berenang, basket, bulu tangkis, dan mengonsumsi obat pelangsing. 


\section{DAFTAR PUSTAKA}

Carrol, L. (2003). Choosing a health club. Retrieved from

Grogan, S. (2007). Body image: Understanding body dissatisfaction in men, women, and children (2nd ed.). London and New York: Routledge Taylor \& Francis Group

Hall, M. (2009). Predictors of body dissatisfaction among adolescent females. Retrieved from www.counselingoutfitters.com

Handayani, A. (2004). Jurnal Online. Pengaruh tingkat partisipasi wanita di fitness centre Bandung dengan penurunan kadar lemak. Diakses dari diunduh pada 16 Mei 2012.

Hurlock, E. B. (2002). Psikologi perkembangan anak: Suatu pendekatan sepanjang rentang kehidupan. Jakarta: Penerbit Erlangga

Hutapea, A. (1996). Gaya hidup sehat: Kiat praktis untuk setiap orang sibuk yang ingin sehat dan fit. Jakarta: PT. Gramedia Pustaka Utama

Ibrahim. (2002). Psikologi wanita. Bandung: Pustaka Hidayah

Lips, H. M. (2006). A new psychology of women: Gender, culture, and ethnicity (3th ed.).New York: The McGraw Hill Companies.

Marchiella, A. (2009). Hubungan antara big five personality dengan body dissatisfaction pada remaja akhir (Skripsi tidak diterbitkan). Universitas Surabaya, Surabaya

Misnadiarly. (2007). Obesitas sebagai faktor risiko beberapa penyakit. Jakarta: Pustaka Obor Populer.

Mumford, D. B., \& Choudry, I. Y. (2000). Body dissatisfaction and eating in slimming and fitness gyms in London and Lahore: A crosscultural study. European Eating Disorders Review. 8, 217-224

Niide, T.K., Davis, J., Tse, A. M., Derauf, C., Harrigan, R. C., \& Yates, A. (2011). Body ideals and body dissatisfaction among a community sample of ethnically diverse adolescents on Kauai, Hawai. Hawaii Journal of Medicine \& Public Health, 3(1), 1-7

Olmsted, M. P. \& McFarlane, T. (2004). Body weight and body image. Women Health Surveilance Report

Prichard, I., \& Tiggemann, M. (2005). Objectification in fitness centers: Selfobjectification, body dissatisfaction, and disordered eating in aerobic instructors and aerobic participants. Sex Roles, 53, (1-2), 19-28

Paxton, S. J., Eisenberg, M. E., \&. Sztainer, D. N., (2006). Prospective predictor of body dissatisfaction in adolescent girl and boys: A five longitudinal study. Developmental Psychology, 42(5), 888-899

Retno, I. S. T (1996). Kiat apik menjadi sehat dan cantik. Jakarta: Gramedia Pustaka Umum

Sivert, S. S. \& Sinanovic, O. (2008). Body dissatisfaction - Is age factor. Philosophy, Sociology, Psychology and History, 7, 5561

Santrock, J. W. (2007). Adolescence (11th ed.). Jakarta: Penerbit Erlangga

Santrock, J. W. (2002). Life-span development $\left(5^{\text {th }}\right.$ ed.). Jakarta: Penerbit Erlangga

Sharkey, J. B. (2003). Kebugaran dan kesehatan. Jakarta: PT. Raja Grafindo Persada

Stice, E. \& Whitenton, K. (2002). Risk factors for body dissatisfaction in adolescent girls: A longitudinal investigation. Developmental Psychology, 38(5), 669-678

Suprapto, M. H. \& Aditomo, A. (2007). Aku dan dia, cantik mana? Perbandingan sosial, body dissatisfaction dan objektivikasi diri. Anima: Indonesian Psychological Journal, 22(2), 188-193

Sarwer, D. B., Thompson, J. K., \& Cash, T. F. (2005). Obesity and body image in adulthood. Psychiatric Clinics of North America, 28, 69-87

Siahaan, R. (2003, Oktober). Simpanan lemak di tubuh anda. Human Health, 2(10), 21-22. 